\title{
Characterization of a Vitellogenin Receptor in the Bumblebee, Bombus lantschouensis (Hymenoptera, Apidae)
}

\author{
Lin Du ${ }^{1,2}$, Mingming Wang ${ }^{3}$, Jilian $\mathrm{Li}^{2}$, Shaoyu $\mathrm{He}^{1}$, Jiaxing Huang ${ }^{2, *(D)}$ and Jie $\mathrm{Wu}^{2, *}$ \\ 1 College of Animal Science and Technology, Yunnan Agricultural University, Kunming 650201, China; \\ dulinbumblebee@sina.com (L.D.); kmhsy@163.com (S.H.) \\ 2 Key Laboratory for Insect-Pollinator Biology of the Ministry of Agriculture and Rural Affairs, \\ Institute of Apicultural Research, Chinese Academy of Agricultural Sciences, Beijing 100093, China; \\ bumblebeelj1@126.com \\ 3 Nanchuan Bureau of Animal Husbandry and Veterinary, Chongqing 408400, China; \\ wangmingming198561@163.com \\ * Correspondence: huangjiaxing@caas.cn (J.H.); apis@vip.sina.com (J.W.); Tel.: +86-10-62591543 (J.W.); \\ Fax: +86-10-62591543 (J.W.)
}

Received: 18 October 2019; Accepted: 10 December 2019; Published: 12 December 2019

\begin{abstract}
The vitellogenin receptor (VgR) belongs to the low-density lipoprotein receptor (LDLR) family, responsible for mediating the endocytosis of vitellogenin (Vg) into the ovaries to promote ovarian growth and oviposition. Here, we cloned and measured $V g R$ gene expression characteristics in the bumblebee Bombus lantschouensis. RNA interference was used to validate $\mathrm{VgR}$ function. The results showed that the full length of the $B L V g R$ cDNA was $5519 \mathrm{bp}$, which included a $5280 \mathrm{bp}$ open reading frame encoding 1759 amino acids (AAs). Sequence alignment revealed that the protein contained 12 LDLa, 5 EGF, 2 EGF-CA and 10 LY domains. Phylogenetic analysis showed that BLVgR and the VgR of Bombus terrestris clustered together and the tree of bumblebees (Bombus) appeared as one clade next to honeybees (Apis). Transcript expression analysis showed that $B L V g R$ was expressed in all tested tissues and showed the highest abundance in the ovaries. $B L V g R$ expression was present in all developmental stages. However, the expression level in larvae was extremely low. In addition, the expression of $B L V g R$ was significantly upregulated after egg laying in both workers and queens. In new emerging workers injected with $5 \mu \mathrm{g}$ of $\mathrm{VgR}$ dsRNA, the expression level of $B L V g R$ was 4-fold lower than that in the GFP dsRNA-injected group after $72 \mathrm{~h}$. Furthermore, $B L V g R$ silencing significantly reduced the number of eggs laid (3.67 \pm 1.96 eggs) and delayed the first egg-laying time $(16.31 \pm 2.07$ days $)$ in worker microcolonies when compared to dsGFP (37.31 \pm 4.09 eggs, $8.15 \pm 0.22$ days) and DEPC-treated water injected controls (16.42 \pm 2.24 eggs, $10.00 \pm 0.37$ days). In conclusion, the $B L V g R$ gene and its reproductive function were explored in the bumblebee $B$. lantschouensis. This gene plays an important role in egg laying time and egg number.
\end{abstract}

Keywords: bumblebee; Bombus lantschouensis; vitellogenin receptor; RNA interference

\section{Introduction}

Bumblebees are one of the most efficient pollinators of many wild plants and crops, especially legumes and Solanaceae plants [1]. Moreover, they play important roles in maintaining the balance of natural ecosystems [2]. Since the 1980s, bumblebees have been used commercially to pollinate greenhouse crops around the world and have conferred significant economic benefits [3,4]. As a result, artificial bumblebee rearing has become important. Reproductive regulation is an important biological process that is vital to bumblebee artificial mass rearing. Vitellogenin $(\mathrm{Vg})$ and the vitellogenin receptor 
$(\mathrm{VgR})$ are two reproductively critical proteins that significantly affect the fecundity of bumblebees. Therefore, full elucidation of the characteristics of $\mathrm{VgR}$ will aid understanding of oviposition regulation.

Insect $\mathrm{VgR}$ belongs to the low-density lipoprotein receptor (LDLR) gene superfamily and plays a critical role in oocyte development by mediating the endocytosis of the major yolk protein precursor $\mathrm{Vg}$ [5]. Vitellogenin is synthesized in the fat body and is internalized by competent oocytes through membrane-bound receptors [6,7]. The main function of $\mathrm{Vg}$ is to provide nutriment for embryos. Moreover, it can protect workers and the queen from oxidative stress that contributes to longevity $[8,9]$. Interestingly, recent studies have shown that $\mathrm{Vg}$ expression also affects the behavior of social insects, as it is related to division of labor $[9,10]$. Insect VgRs and all other LDLR family receptors share five structural domains: the ligand-binding domain (LBD), made up of cysteine-rich repeats; the epidermal growth factor (EGF)-precursor homology domain, characterized by a recurrent 'YWXD' motif (YWXD repeats); the O-linked sugar domain of unknown function; the transmembrane domain anchoring the receptor in the plasma membrane; and the cytoplasmic domain containing an internalization signal [5]. In 1986, the VgR protein from the oocytes of the locust Locusta migratoria was first identified and purified [11]. Since then, it has been identified in a variety of economic insects $[12,13]$ and agricultural pests [14-17]. In 2004, the cloning of the first hymenopteran $V g R$ cDNA from the imported fire ant Solenopsis invicta ( $\mathrm{SiVgR}$ ) was reported, and this $V g R$ was upregulated by methoprene, a juvenile hormone (JH) analog [18]. In 2006, RNAi technology was first used to analyze VgR function in the cockroach Blattella germanica [19]. However, the first silencing of hymenoptera VgR with RNAi was achieved in 2009 [20]. The expression characteristics of VgR from the honeybee Apis mellifera in the queen and workers were also studied, and the results suggested that $\mathrm{VgR}$ is not caste or tissue specific. It was detected in all sexes and outside the ovary [21]. To date, the characteristics of $\mathrm{VgR}$ have not been explored in bumblebees.

RNA interference is a technology for posttranscriptional gene silencing that has been developed as a powerful tool for studying gene function in a variety of organisms [22]. A variety of efficient means to transport double-stranded RNA (dsRNA) into organisms has been developed including microinjection, feeding and transgenic plant expression [23-25]. RNAi has achieved prodigious progress in insect pest control and economic insect biology research $[20,25]$. In recent years, RNAi has been used to study the regulation of target gene expression, caste differentiation and disease control in honeybees [26-28]. However, there have been no reports on reproductive inhibition by using RNAi in bumblebees.

The bumblebee Bombus lantschouensis is a polylectic and primitively eusocial bee that is widely distributed in medium-elevation mountains and plateaus in northern China [29]. It is an important pollinator of wild plants and crops and has been selected as the native species applied to pollinate greenhouse crops. A recent study indicates that the pollination efficiency of this species exceeds that of honeybees. Interestingly, B. lantschouensis prefers to visit plants with less pollen and nectar than honeybees [30]. The molecular mechanisms of reproduction, such as the female fertility regulation, are a vital aspect of artificial mass rearing. Vitellogenin and the vitellogenin receptor are important genes for insect fecundity [6]. Therefore, it is necessary to explore the effect of BLVgR on female reproduction in B. lantschouensis.

Understanding the molecular mechanisms of reproductive regulation is critical for bumblebee artificial rearing. In the present study, the $\mathrm{Vg}$ transporter protein $\mathrm{VgR}$ gene of a bumblebee (B. lantschouensis) was cloned, and its expression profile was checked in different tissues, developmental stages and reproductive statuses. RNAi was used to validate the function of $B L V g R$ in ovarian activation, first egg laying time and number of eggs laid. These results help us to understand the basic knowledge of $\mathrm{VgR}$ in bumblebee commercial rearing. 


\section{Materials and Methods}

\subsection{Samples}

Bumblebees (B. lantschouensis) were collected from the rearing room the Institute of Apicultural Research, Chinese Academy of Agricultural Science, Beijing, China. Bumblebees were sampled from thirty independent colonies that were raised in an artificial breeding room (in constant darkness with a temperature of $28 \pm 0.5{ }^{\circ} \mathrm{C}$ and $60 \pm 5 \%$ relative humidity) and fed fresh frozen pollen and a 50\% sugar solution every other day [31]. Different tissues from 18 egg-laying queens were sampled. The tissues were as follows: antenna (AN), head (HD), thorax (TH), leg (LG), epidermis (EP), midgut (MG), ovary (OV), fat body (FB) and venom gland (VG). All tissues were dissected and frozen in liquid nitrogen immediately. Tissues from six bees as a biological replicate were pooled, and total RNA was extracted. Samples from three different development stages except the egg stage of bumblebee workers, were obtained individually at the following stages: within $48 \mathrm{~h}$ of larval hatching (Lar), pupae with an unpigmented body cuticle and white eyes (Pw), pink eyes (Pp), and brown eyes (Pb), pupae with dark brown eyes and a light-pigmented thorax $(\mathrm{Pbl})$, and pupae with brown eyes and a dark-pigmented cuticle (Pbd). Eggs were sampled within 24 h, eighteen eggs were collected (six eggs in each biological replicate). The expression level of VgR in the ovary was measured at egg-laying and non-egg-laying statuses of queens and workers. Each reproductive status had three samples [32]. All samples were stored at $-80{ }^{\circ} \mathrm{C}$ until use.

\subsection{RNA Extraction and Synthesis of $c D N A$}

Total RNA was extracted from all samples with TRIzol reagent (Invitrogen, Carlsbad, CA, USA) following the manufacturer's instructions. The purity of the RNA was assessed using a NanoDrop 2000 spectrophotometer (Thermo Fisher Scientific, Waltham, MA, USA) at 260/280 nm, and RNA integrity was screened by $1.5 \%(\mathrm{w} / \mathrm{v})$ agarose gel electrophoresis. The first strand of cDNA was synthesized according to the instructions of the Reverse Transcription kit (Takara, Dalian, China). The reaction conditions were as follows: $42{ }^{\circ} \mathrm{C}$ for $30 \mathrm{~min}, 99{ }^{\circ} \mathrm{C}$ for $5 \mathrm{~min}$, and $5{ }^{\circ} \mathrm{C}$ for $5 \mathrm{~min}$, after which the product was stored at $-20^{\circ} \mathrm{C}$ until use.

\subsection{Molecular Cloning of $B L V g R$}

To obtain a specific fragment of the $B L V g R$ cDNA, primers (Table 1) were designed and synthesized according to the predicted $V g R$ sequence of Bombus terrestris (GenBank accession number: LOC100649042). The PCR amplification conditions were as follows: $94{ }^{\circ} \mathrm{C}$ for $3 \mathrm{~min}, 35$ cycles of $94{ }^{\circ} \mathrm{C}$ for $30 \mathrm{~s}, 55^{\circ} \mathrm{C}$ for $50 \mathrm{~s}$ and $72{ }^{\circ} \mathrm{C}$ for $1 \mathrm{~min}$, and $72{ }^{\circ} \mathrm{C}$ for $10 \mathrm{~min}$. The PCR products were ligated into the pMD19-T vector (Takara Bio Inc., Dalian, China), which was then transformed into Trans1-T1 E. coli competent cells (Transgen Biotech, Beijing, China). Ampicillin resistance and white-blue screening were used to select the positive clone. Positive colonies were sent for sequencing by the Sino GenoMax Company (Beijing, China) using the Sanger method.

Full-length cDNA amplification was performed using a SMARTer rapid amplification of cDNA ends (RACE) amplification kit (Clontech, Mountain View, CA, USA) according to the manufacturer's recommendations with the appropriate primers (Table 1). PCR was carried out with 5 cycles of $94^{\circ} \mathrm{C}$ for $30 \mathrm{~s}$ and $72{ }^{\circ} \mathrm{C}$ for $3 \mathrm{~min} ; 5$ cycles of $94{ }^{\circ} \mathrm{C}$ for $30 \mathrm{~s}, 70{ }^{\circ} \mathrm{C}$ for $30 \mathrm{~s}$ and $72{ }^{\circ} \mathrm{C}$ for $3 \mathrm{~min}$; and $27 \mathrm{cycles}$ of $94{ }^{\circ} \mathrm{C}$ for $30 \mathrm{~s}, 68^{\circ} \mathrm{C}$ for $30 \mathrm{~s}$ and $72{ }^{\circ} \mathrm{C}$ for $3 \mathrm{~min}$. The amplified DNA fragment was cloned and sequenced to both ends.

\subsection{Sequence Analysis}

Sequences were assembled, and the open reading frame (ORF) was predicted using BioEdit 7.2.5 software (http://www.mbio.ncsu.edu/BioEdit/bioedit.html). The molecular weight (MW), theoretical isoelectric point $(\mathrm{pI})$, properties of the amino acid residues, and protein hydropathy were assessed using the European Molecular Biology Open Software Suite (EMBOSS) (http://emboss.sourceforge. 
net/) [33]. The online TMHMM-2.0 program was used to analyze the protein transmembrane domain (http://www.cbs.dtu.dk/services/TMHMM-2.0/) [34]. The signal peptide position was predicted using SignalP-5.0 (http://www.cbs.dtu.dk/services/SignalP-5.0/) [35]. We download homologous $\mathrm{VgR}$ amino acid sequences from GenBank, including those from the following species: B. terrestris (XP_003402703.1), Bombus impatiens (XP_012241122.1), Apis cerana (PBC31775.1), Apis mellifera (XP_026295652.1), Apis dorsata (XP_006610571.1), Apis florea (XP_012350206.1), Solenopsis invicta (NP_001291525.1), Nasonia vitripennis (XP_008217630.1), Drosophila melanogaster (NP_996433.1), Drosophila sechellia (XP_002042769.1), Drosophila yakuba (XP_002100545.2), Drosophila erecta (XP_001978195.1), Drosophila ananassae (XP_001966853.1), Drosophila persimilis (EDW29780.1), Drosophila pseudoobscura (XP_001354886.2), Drosophila willistoni (XP_002064208.2), Drosophila virilis (XP_002054982.2), Aedes aegypti (AAC28497.1), Anopheles gambiae (XP_310672.5), Blattella germanica (CAJ19121.1), Rhyparobia maderae (BAE93218.1), Periplaneta americana (BAC02725.2), and Acyrthosiphon pisum (XP_016657813.1). The SMART program (http://smart.embl-heidelberg.de/) was used to identify conserved domains [36]. Evolutionary analyses were conducted in MEGA X [37]. The VgR sequence of $A$. pisum was used as an outgroup. The evolutionary history was inferred by using the maximum likelihood method and general reversible chloroplast plus frequency model, and the reliability of the tree was assessed with 1000 bootstrap replications. Branches corresponding to partitions reproduced in less than 50\% bootstrap replicates are collapsed [38].

Table 1. Primers used for the identification and analysis of the B. lantschouensis $V g R(B L V g R)$.

\begin{tabular}{|c|c|c|}
\hline Purpose & Name & Primer Sequence $\left(5^{\prime}-3^{\prime}\right)$ \\
\hline \multirow{2}{*}{ cDNA cloning } & VgRF & ACTCATGTTTGTGCCAACCTG \\
\hline & VgRR & TTGGATGGTACAGATCGAAGG \\
\hline \multirow{4}{*}{ RACE } & $5^{\prime} \mathrm{VgR9F}$ & TCGAGGTGCAAGCATGAGGATCAGTT \\
\hline & $3^{\prime} \mathrm{VgR9R}$ & GCGTTTCTTTGGCATGTTACGCTCT \\
\hline & UPM-Long & CTAATACGACTCACTATAGC \\
\hline & UPM-Short & TCACCGCATTCATCTTCC \\
\hline \multirow{6}{*}{ Real-time PCR } & FVgRF & GTGTGCCTGTTATCTAATGCTGAT \\
\hline & FVgRR & TTCATCTTCACCGTTAGGACAATC \\
\hline & $\beta$-actinF & CGACTACCTCATGAAGATT \\
\hline & $\beta$-actinR & CGACGTAACAAAGTTTCTC \\
\hline & GAPDH-F & GCTGGAGCTGAATATGTTGTAGAATC \\
\hline & GAPDH-R & AGTAGTGCAGGAAGCATTAGAGATAACT \\
\hline \multirow{8}{*}{ RNAi } & RNAiVgR1F & GTTTCAATGTAAAAACGGCGACT \\
\hline & RNAiVgR1R & TCGTTCTTTGGACAATCTGTAACG \\
\hline & T7RNAiVgR1F & GGATCCTAATACGACTCACTATAGGGTTTCAATGTAAAAACGGCGACT \\
\hline & T7RNAiVgR1R & GGATCCTAATACGACTCACTATAGGTCGTTCTTTGGACAATCTGTAACG \\
\hline & GFP-F & CCACAAGTTCAGCGTGTCCG \\
\hline & GFP-R & AAGTTCACCTTGATGCCGTTCT \\
\hline & T7GFP-F & GGATCCTAATACGACTCACTATAGCCACAAGTTCAGCGTGTCCG \\
\hline & T7GFP-R & GGATCCTAATACGACTCACTATAGAAGTTCACCTTGATGCCGTTCT \\
\hline
\end{tabular}

\subsection{BLVgR Expression Analysis Using Quantitative RT-PCR}

The expression levels of $B L V g R$ mRNA in different tissues, developmental stages and reproductive status of workers and queens, as well as the results of different RNAi treatments, were analyzed by real-time quantitative PCR using a Stratagene Mx3000 real-time PCR system (Agilent, USA). First-strand cDNA samples, were diluted $(1: 10 v / v)$ with DEPC-treated water. Amplification was carried out in a $20 \mu \mathrm{L}$ reaction volume containing $10 \mu \mathrm{L}$ of $10 \times$ TB Green Master Mix (Takara, Dalian, China), $2 \mu \mathrm{L} \mathrm{cDNA}$, and $0.5 \mu \mathrm{L}$ of each $10 \mu \mathrm{m}$ primer (Table 1). Quantitative measurements were normalized using $\beta$-actin and GAPDH. The qPCR conditions were as follows $95^{\circ} \mathrm{C}$ for $30 \mathrm{~s}$, followed by 40 cycles of $95^{\circ} \mathrm{C}$ for $5 \mathrm{~s}$, and $63^{\circ} \mathrm{C}$ for $1 \mathrm{~min}$. Each assay was performed in triplicate and repeated 
with three independent samples. The relative quantities of $B L V g R$ transcripts were calculated using the comparative Ct method [39].

\subsection{RNA Interference}

To synthesize double-stranded RNA (dsRNA), a specific fragment was amplified with two T7 promoter primers (Table 1). The amplification conditions were predenaturing at $94{ }^{\circ} \mathrm{C}$ for $5 \mathrm{~min}$, followed by 35 cycles of denaturing at $94^{\circ} \mathrm{C}$ for $30 \mathrm{~s}$, annealing at $58^{\circ} \mathrm{C}$ for $1 \mathrm{~min}$ and extension at $72{ }^{\circ} \mathrm{C}$ for $1 \mathrm{~min}$, with a final extension at $72{ }^{\circ} \mathrm{C}$ for $10 \mathrm{~min}$. The GFP gene (ACY56286) and DEPC-treated water were used as a negative control $[17,23,40]$. Double stranded RNA was synthesized using the T7 RiboMAX ${ }^{\mathrm{TM}}$ Express RNAi System (Promega, Madison, WI, USA) according to the manufacturer's suggestions. The dsRNA was dissolved in the appropriate volume of DEPC-treated water and stored at $-80^{\circ} \mathrm{C}$.

Newly emerged workers (within $24 \mathrm{~h}$ ) from five colonies were injected with $10 \mu \mathrm{L}$ (500 ng/ $\mu \mathrm{L}$ ) of a dsRNA solution containing dsVgR $(\mathrm{N}=93)$, dsGFP $(\mathrm{N}=93)$ or DEPC-treated water $(\mathrm{N}=114)$. The bees were injected through the conjunction between the 5th and 6th abdominal sternum using a FemtoJet micro-injector [41]. After injection, three bees were selected randomly to form a micro-colony individually $(21 \times 14 \times 7 \mathrm{~cm}$ contained four colonies to share the food). To obtain the optimal dose of microinjection, eighteen microcolonies including nine colonies of $\mathrm{dsVgR}$ and nine colonies of dsGFP were used to test three different concentrations $(0.2,1$ and $5 \mu \mathrm{g})$ of dsRNA with three biological replicates. The expression of $\mathrm{VgR}$ in the ovary was used to measure the silencing efficiency with $\mathrm{qPCR}$ at $72 \mathrm{~h}$ after the injection. The concentration of $5 \mu \mathrm{g}$ was the best silencing efficiency and this concentration was used to evaluate the effect of silencing on egg laying. The number of eggs laid within 15 days and the first egg laying time were counted and recorded based on 13 microcolonies of dsVgR (39 workers), 13 microcolonies of dsGFP (39 workers) and 19 microcolonies of DEPC-treated water ( 57 workers) after injection. The laying status was checked every day. When the worker laid eggs, we removed the eggs and recorded the number of eggs. The microcolonies that remained were used to observe the development of the ovaries.

\subsection{Data Analysis}

All data are presented as mean \pm SE. Before the statistical test, the data were tested for normality. The difference of treatments was analyzed by one-way analysis of variance (ANOVA) followed by Tukey post hoc test with R-project software version 3.5.1 (https://cran.r-project.org).

\section{Results}

\subsection{Full-Length $c D N A$ of $B L V g R$}

The specific amplification fragments and the $3^{\prime}$ end and $5^{\prime}$ end RACE sequences were merged with BioEdit. The results showed that the full-length cDNA of $B L V g R$ (GenBank ID: MN217253) was $5519 \mathrm{bp}$ and contained a $63 \mathrm{bp} 5^{\prime}$ UTR and $179 \mathrm{bp} 3^{\prime}$ UTR with a polyadenylation signal (AATAAA) (Figure 1). The ORF was composed of 5280 nucleotides encoding 1759 amino acids. The initiation codon (ATG) and stop codon (TAG) were present at positions 64-66 and 5341-5343, respectively. The predicted molecular weight of $B L V g R$ was $198.131 \mathrm{kDa}$, and the theoretical pI was 5.9. Moreover, $B L V g R$ contained a signal peptide with a potential cleavage site between amino acid residues 27 and 28 .

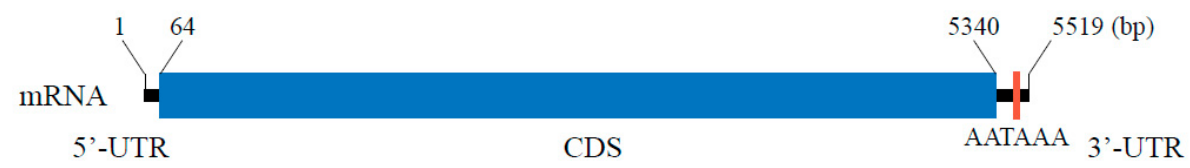

Figure 1. mRNA structure of $B L V g R$ in the bumblebee (Bombus lantschouensis). The numbers indicate the position in the sequence. The full-length BLVgR cDNA sequence is $5519 \mathrm{bp}$. The 5' UTR and 3' UTR are 63 and $179 \mathrm{bp}$. A polyadenylation signal (AATAAA) is found the end of the mRNA sequence. 


\subsection{Sequence and Phylogenetic Analysis of BLVgR}

The analysis of conserved domains showed that BLVgR is a member of the LDLR superfamily of receptors, and the BLVgR protein was most similar to the $\mathrm{VgR}$ protein sequence of $B$. terrestris (XP_003402703.1), followed by that of B. impatiens (XP_012241122.1), as expected due to their similar taxonomic positions (Figure 2). BLVgR exhibited two ligand-binding domains (LBDs) with four class A cysteine-rich repeats (LDLa) in the first domain (LBD1) and eight repeats in the second domain (LBD2). Each LBD was followed by an epidermal growth factor (EGF)-like domain. The first EGF-like domain contained a calcium-binding domain, seven LY domains and three EGF domains, whereas only a calcium-binding domain, three LY domains and two EGF domains were found in the second. The second EGF-like domain was followed by a transmembrane domain and a cytoplasmic domain (Figure 2). Therefore, this sequence is considered to be the full-length cDNA sequence of B. lantschouensis.

To inspect the evolutionary relationships between BLVgR and other VgRs from different species, a phylogenetic tree of VgRs was constructed (Figure 2). As expected, VgRs of bumblebees (Bombus) appeared as one clade next to honeybees (Apis), and an ant (Solenopsis) was closer to the bees than the parasitic wasp (Nasonia).

(a)

(b)

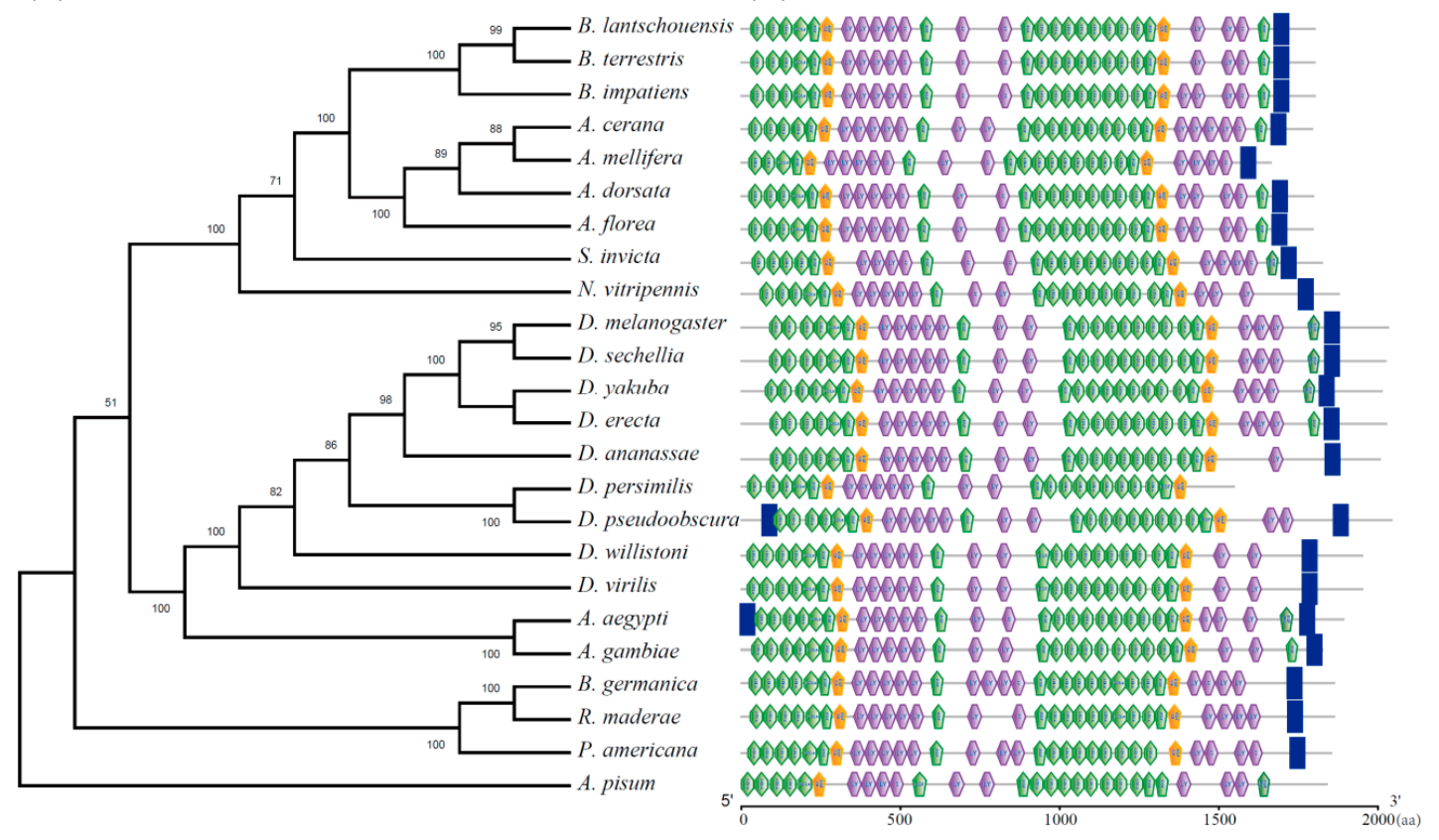

Figure 2. Diagrammatic phylogenetic relationship and structure comparisons of BLVgR with sequences from other insects: (a) Phylogenetic analysis of BLVgR with the vitellogenin receptors of insects from different orders. The phylogenetic tree was constructed by using MEGA X with a statistical method of maximum-likelihood. The $\mathrm{VgR}$ sequence of $A$. pisum was used as an outgroup. The numbers indicate bootstrap support values (\%) based on 1000 replicates. Branches corresponding to partitions reproduced in less than 50\% bootstrap replicates are collapsed. (b) Comparison of BLVgR modular domains with those of other insects. LDLa, low-density lipoprotein receptor domain class A (hexagon with green); EGF, epidermal growth factor-like domain (pentagon with green); EGF_CA, calcium-binding EGF-like domain (pentagon with yellow); LY, low-density lipoprotein receptor YWTD protein (hexagon with purple); transmembrane domain (tetragon with blue).

\subsection{Expression Patterns of BLVgRs in Different Tissues, Developmental Stages and Reproductive Status}

The BlVgR transcript was detected in all tissues, and the highest transcript levels were detected in the ovary. Except in the ovary, the expression level was not significantly different between 
different tissues $(p>0.05)$ (Figure 3a). Between the various developmental stages, relatively higher transcript abundance of $B L V g R$ was observed in the eggs than in the other developmental stages. However, it dropped to the lowest level at the larval stage. There were no significant differences between any pupal stages (Figure $3 b$ ). For both castes, queens and workers, individuals who were laying eggs had significantly higher transcript levels of $B L V g R$ than non-laying individuals $(p<0.01$; Figure $3 c, d)$. Therefore, $B L V g R$ was positively correlated with an enhanced female reproductive status.

(a)

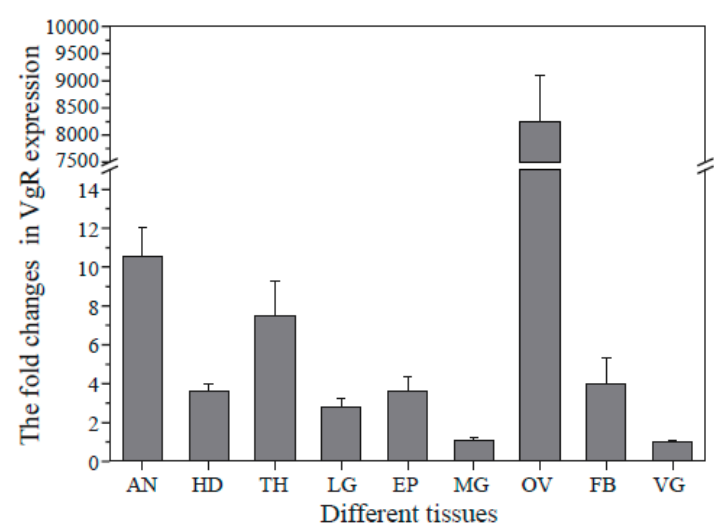

(c)

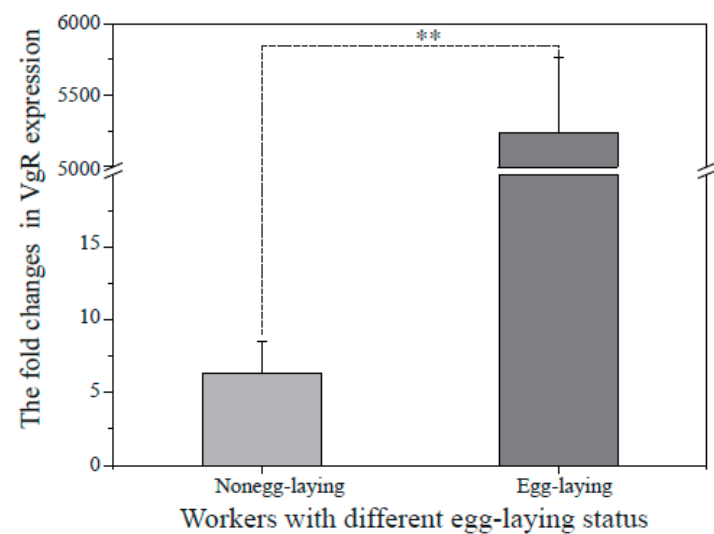

(b)

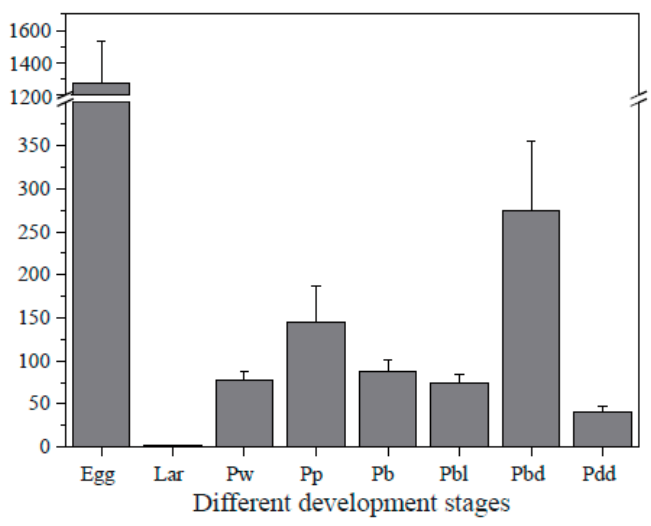

(d)

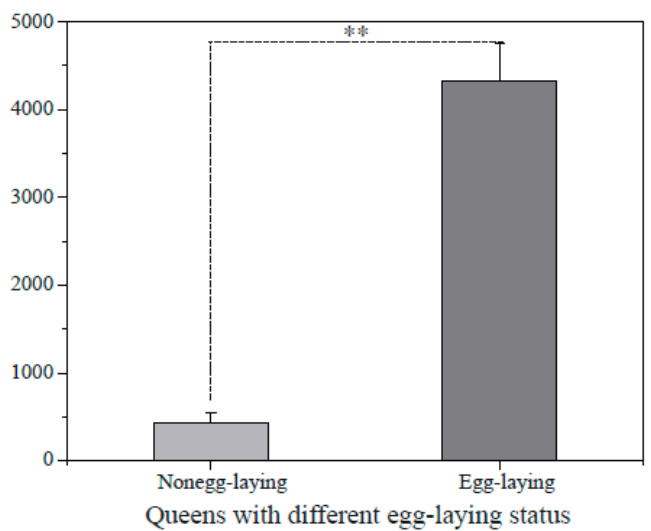

Figure 3. Analysis of relative $B L V g R$ expression in different tissues, developmental stages and reproductive status in bumblebees (B. lantschouensis). (a) Analysis of relative $B L V g R$ expression in different tissues: antenna (AN), head (HD), thorax (TH), leg (LG), epidermis (EP), midgut (MG), ovary (OV), fat body (FB), and venom gland (VG) $(\mathrm{F}=91.811, \mathrm{df}=(8,72), p<0.05)$. (b) Analysis of relative $B L V g R$ expression at different developmental stages: Egg (within $24 \mathrm{~h}$ of laying), Lar (within $48 \mathrm{~h}$ of larvae after hatching), Pw (white-eyed pupae with an unpigmented cuticle), Pp (pink-eyed pupae with an unpigmented cuticle), $\mathrm{Pb}$ (brown-eyed pupae with an unpigmented cuticle), $\mathrm{Pbl}$ (brown-eyed pupae with thoracic pigmentation), Pbd (brown eyes with a dark-pigmented cuticle), and Pdd (dark-eye pupae with a dark-pigmented cuticle) $(\mathrm{F}=18.373, \mathrm{df}=(7,64), p<0.05)$. (c) Differences in the expression of the $B L V g R$ gene in B. lantschouensis workers with different reproductive status. Three egg-laying and non-egg-laying workers were sampled. The expression level of $B L V g R$ was significantly increased in egg-laying workers compared with non-egg-laying workers $(\mathrm{F}=95.588$, $\mathrm{df}=(1,16), p<0.01)$. (d) Differences in the expression of the $B L V g R$ gene in queens with different reproductive status. Three egg-laying and non-egg-laying queens were sampled. The expression level of $B L V g R$ was significantly increased in egg-laying queens compared with non-egg-laying queens $(\mathrm{F}=48.977, \mathrm{df}=(1,16), p<0.01)$. The asterisks above the error bar indicate that the expression levels were significantly different $(p<0.01)$. 


\subsection{RNA Interference}

To explore the efficiency of dsRNA injection, $B L V g R$ expression levels were measured by qPCR. The $B L V g R$ transcript levels of dsVgR-injected workers were significantly decreased by 4-fold compared to those of the dsGFP group at $72 \mathrm{~h}$ after dsRNA injection (Figure 4 ). The number of eggs laid by workers within 15 days after injection was significantly decreased in the dsVgR group compared to the dsGFP $(\mathrm{F}=54.685, \mathrm{df}=(1,24), p<0.01)$ and DEPC-treated water $(\mathrm{F}=16.1448, \mathrm{df}=(1,24), p<0.01)$. The numbers of eggs were lower by $74.5 \%$ and $90.1 \%$ in the workers injected with dsVgR compared to the DEPC-treated water and dsGFP groups, respectively (Figure 5a). Moreover, the time until first egg laying in the dsVgR-treated workers was significantly longer than in the dsGFP $(F=15.287, \mathrm{df}=(1,24)$, $p<0.01)$ and DEPC-treated groups $(\mathrm{F}=12.854, \mathrm{df}=(1,30), p<0.01)(16.31 \pm 2.07,8.15 \pm 0.22$, and $10.00 \pm 0.37$ days, respectively). Colonies treated with dsVgR were delayed $8 \mathrm{~d}$ and $6 \mathrm{~d}$ compared to the colonies treated with dsGFP and DEPC-treated water (Figure 5b). The dissection of ovaries showed the degree of ovary swelling was lower compared to that in the dsGFP groups (Figure 6).

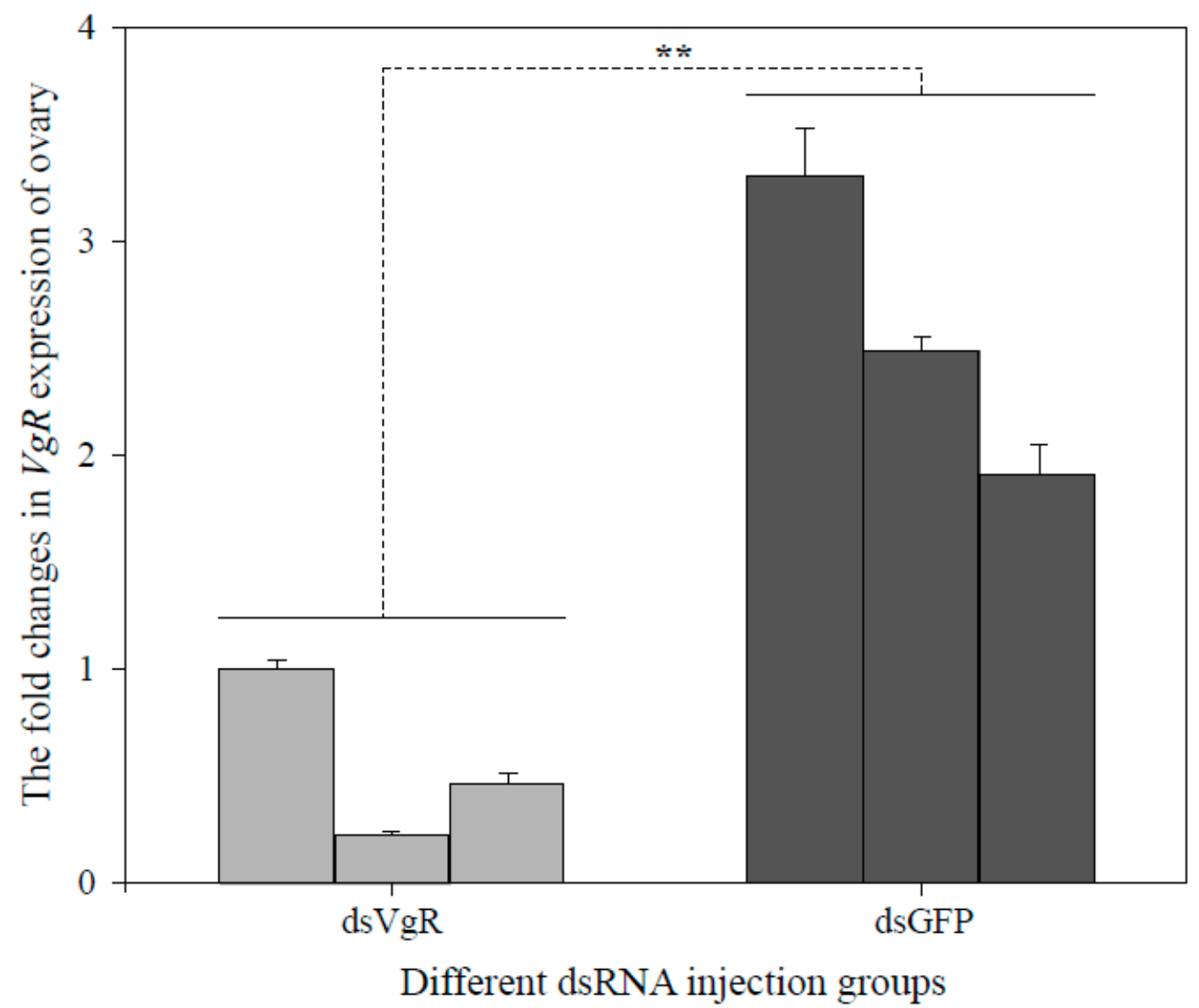

Figure 4. The transcript level of $V g R$ in ovaries of bumblebee workers that were subjected to RNA interference. The expression levels of $B L V g R$ were determined by qPCR following the injection of $\mathrm{dsVgR}$ after $72 \mathrm{~h}$. Three microcolonies of each treatment (dsVgR and dsGFP) were sampled. The dsGFP treatment group was used as a control. The expression level of VgR was significantly decreased $(* * p<0.01)$. 
(a)

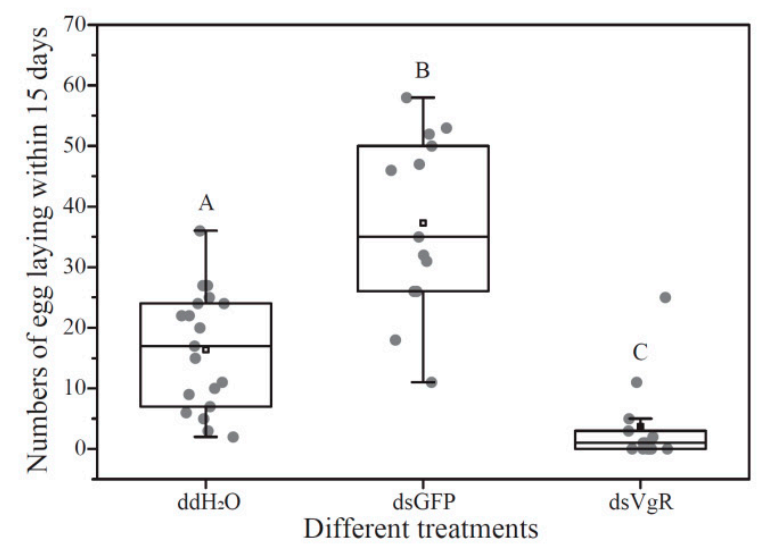

(b)

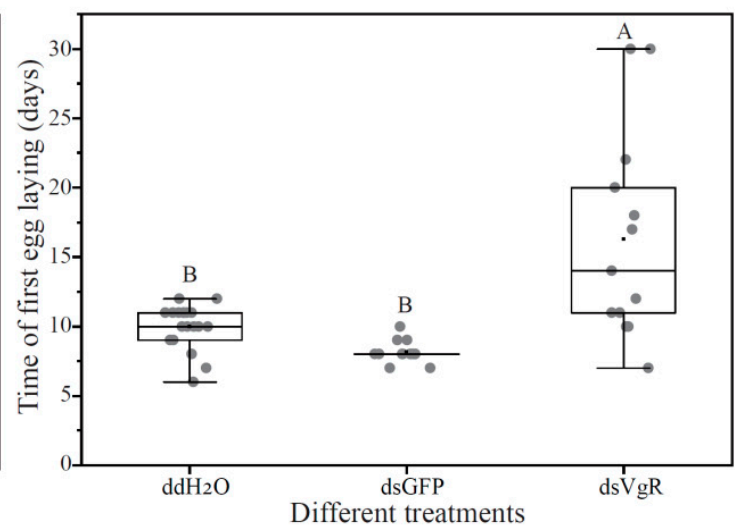

Figure 5. The fecundity including the number of eggs laid and the first egg-laying time was evaluated after dsRNA RNAi-mediated knockdown of $\mathrm{VgR}$. The total number of eggs laid in each microcolony was counted within 15 days after injection. The number of microcolonies in dsVgR, dsGFP and DEPC-treated water groups was 13,13, and 19. (a) The difference of egg laying number under different treatments. Eggs were removed every day and the number was counted. (b) The difference of first egg laying time under different treatments. Egg laying status was checked every day. When the first egg was observed, the first egg laying time was recorded. Different letters represent a significant level $(p<0.01)$.

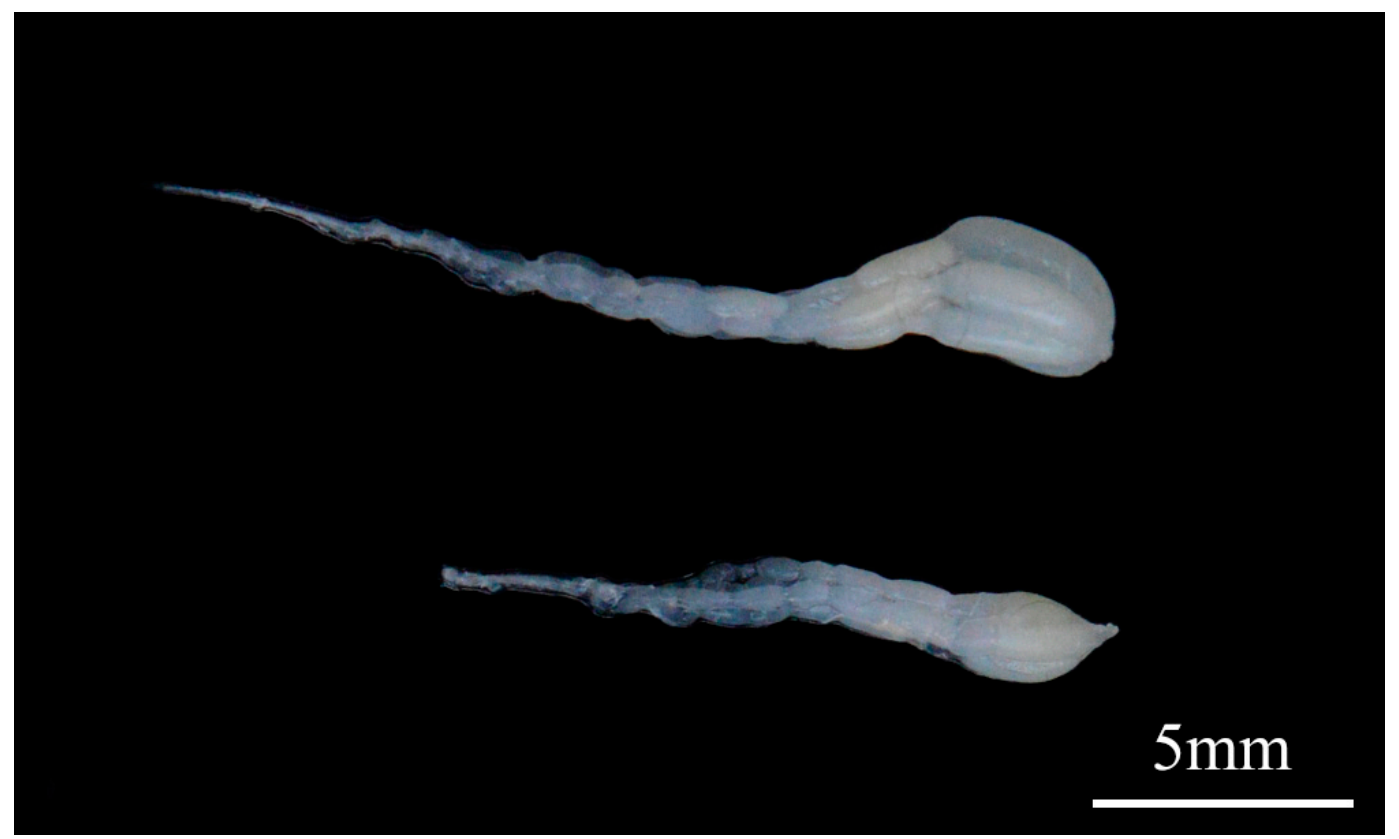

Figure 6. Ovary development status was evaluated after the RNAi-mediated knockdown of $B L V g R$. Newly emerged adult workers were injected with dsGFP and dsVgR. Ovaries were dissected under dissection microscopy and photographed with a NIKON (D750) camera 7 days after the injection. The ovary on the top was from the dsGFP group, and the ovary on the bottom was from the dsVgR group.

\section{Discussion}

The understanding of the molecular mechanisms of insect reproductive regulation has reached a new level, especially in social insects [20]. The bumblebee, B. lantschouensis is a social bee that is endemic to northern China and has been selected for artificial rearing and crop pollination $[29,32,42]$. The development of bee colonies is highly dependent on the ovary activation in the queen, in which 
the biosynthesis and transport of $\mathrm{Vg}$ are vital [43]. $\mathrm{VgR}$ as a transporter of $\mathrm{Vg}$, is essential for ovary activation. Moreover, $\mathrm{VgR}$ has been demonstrated to not only mediate the transport of $\mathrm{Vg}$ but also play an important role in vitellogenesis $[18,44]$. In the present study, the complete $V g R$ cDNA sequence of B. lantschouensis was identified, which, to our knowledge, represents the first report of a VgR from a bumblebee. It was demonstated that BLVgR affects the first egg-laying duration and the number of eggs laid in workers. These findings will benefit from studying the mechanism of vitellogenin transport and absorption in bumblebees.

The domains present in BLVgR indicate that BLVgR is a member of the LDLR family (Figure 2). BLVgR was shown to contain two ligand-binding domains with four and eight LDLa repeats, respectively, and the BLVgR LDLa repeats present an architecture that is closer to the VgR architecture of A. mellifera, S. invicta and N. vitripennis [18,21]. However, the number of LDLa repeats in Hymenoptera differ from that in other insects. For example, there are four and seven LDLa repeats in Lepidoptera [12,15], five and eight repeats in Diptera and Blattaria [45]. Additionally, BLVgR contains two EGF-like domains, both of which include a calcium-binding site similar to the VgRs of A. mellifera, S. invicta and D. melanogaster. The O-linked sugar domain is in the last EGF-like domain and the TM domain [5,46]. In this study, no O-linked sugar domain was found in BLVgR, which is consistent with the VgRs of B. dorsalis and S. invicta [18,47], and is different from A. mellifera, L. maderae, and $N$. lugens $[17,21,45]$. This indicates that the O-linked sugar domain motif is not the common functional domain of vertebrate VgRs [48].

For long time, it was assumed that vitellogenin receptor expression is highly tissue specific and is restricted to the ovaries of the females of insects $[15,17,45]$. However, it was found that the $A m V g R$ of A. mellifera is expressed not only in the ovarian tissues of reproductive females but also in males [21]. This situation contrasts with observations made in S. invicta in which VgR expression is limited to the ovaries [20]. In the present study, $B L V g R$ was expressed in all tested tissues and showed the highest abundance in the ovaries, which may be related to the pleiotropic biological functions of its ligand $\mathrm{Vg}$ (Figure 3c). Besides the reproductive process, it has been demonstrated that vitellogenin is also involved in regulating the longevity of the queen and workers through epidemic inhibition of the antioxidant response [49]. In addition, it is also related to the regulation of JH titer and co-opted to regulate division of labor in workers [8]. However, recent studies have found that the LDLR family receptor has the function of signal transmission, which directly transmits signals on the target cell's plasma membrane by interacting with the cytoplasmic adaptor and the scaffold protein $[50,51]$. Therefore, the tissue-specific expression of BLVgR may be related to the alternative function of its ligand and the multi-function of the receptor.

The expression of $B L V g R$ gene was irregular throughout stages before emerging. The high expression at the egg, PW and Pbd stage suggest that it is essential to metamorphosis in these stages. In addition, its almost disappearance in the larval stage means the function of $\mathrm{VgR}$ is minor. Interestingly, our results are consistent with the Vg expression changes of the bumblebee, Bombus hypocrita [52]. The expression of $\mathrm{Vg}$ mRNA in females was detected at the Pw stage, and increased during the entire pupal development with a peak at the Pbd stage. This suggests that the transcriptional changes of $\mathrm{VgR}$ is related to it ligand concentration.

$B L V g R$ expression was closely correlated with the ovarian development of adult females. Significant differences in the expression of $B L V g R$ were observed in different egg-laying statuses. The levels of $B L V g R$ transcripts were increased in the ovaries of egg-laying queens and workers in comparison to virgin queens and naïve workers (Figure $3 \mathrm{c}, \mathrm{d}$ ). In $A$. mellifera, the $A m V g R$ transcript level was increased in the ovaries of egg-laying queens in comparison to virgin queens as well as workers [21]. In A. aegypti, VgR transcript levels in the ovaries rapidly increase after adult eclosion and continue to rise as the ovaries become vitelogenic, reaching peak levels $24 \mathrm{~h}$ after a blood meal [53]. However, in cockroaches, the developmental profile of $\mathrm{VgR}$ shows the highest levels in the immature ovaries of final-instar female nymphs and in the early previtellogenic period [45]. Moreover, the $\operatorname{Si} \mathrm{g} R$ transcript is present at higher levels in virgin alate females than in reproductively active queens in 
S. invicta [18]. The different spatiotemporal dynamics of $\mathrm{VgR}$ may be caused by the different functions of $\mathrm{VgR}$ in different organisms such as observed in A. mellifera [21].

RNAi is a powerful tool for exploring gene function [16]. In 2009, the first study achieving successful posttranscriptional silencing of $V g R$ was reported in Hymenoptera [20]. In bumblebees, RNAi is an effective method for gene function verification. Kim et al. demonstrated expression regulation by reducing Bi-Tf or Bi-FerHCH levels in the fat body via RNA interference in bumblebee [54]. Silencing of $V g R$ in $S$. invicta led to a significant decrease in $S i V g R$ expression in queen ovaries derived from dsVgR-injected pupae and stunted oocytes showing no $V g R$ signal; the blocking effect continued for at least 10 days upon the eclosion of virgin queens [20]. Interestingly, the silencing of $V g R$ in cockroaches significantly decreased $N l V g R$ transcript and protein levels after injection with dsRNA, and inhibited Vg endocytosis in the oocytes. Moreover, silencing $N l V g R$ causes a delay in ovarian development and inhibition of oviposition [17]. In this study, newly emerged workers and $5 \mu \mathrm{g} \mathrm{dsVgR}$ per bee were selected as the appropriate stage and the optimal dose for microinjection. After dsVgR treatment, the mRNA expression of $B L V g R$ was significantly lower than in the dsGFP group (Figure 4). As expected, the number of eggs laid in the dsVgR-treated groups was lower than that in the controls (Figure 5a). In contrast, the time to the first egg laying was longer (Figure 5b). Similar results were observed in H. armigera [15] and N. lugens [17]. However, the difference in egg production between the dsGFP group and the DEPC group was significant in our study. This may be caused by the injection of dsGFP that lead to the high expression of immune genes and the high expression of immune genes will benefit egg laying $[55,56]$.

In summary, we have demonstrated that RNAi can successfully silence $B L V g R$ to affect the fertility of female bumblebees. However, this study examined the function of $\mathrm{VgR}$ in worker bees without examining queens. Both workers and queens develop from diploid fertilized eggs and share the same genes. It has been reported in B. terrestris that the microcolonies (groups of three workers isolated from the queen) can be used to estimate egg numbers, the delay before egg laying, larval production, and adult offspring fitness [57]. Microcolonies are also used to measure the lethal and sublethal effects of insecticidal proteins expressed in transgenic plants, as well as growth efficiency associated with different pollen types in bumblebees [58,59]. In conclusion, regardless of essential characteristics, this study clearly indicates that $\mathrm{VgR}$ plays an important role in female oviposition and ovarian maturation in bumblebees.

\section{Conclusions}

In conclusion, we identified the cDNA and analyzed the molecular characteristics of $B L V g R$ from the bumblebee $B$. lantschouensis. This gene is structurally conserved compared with the homologous genes of other species. The expression patterns of $B L V g R$ in different tissues, development stages, and reproductive status were identified. In addition, the function of $B L V g R$ was verified by RNAi technology. The injection of $\mathrm{dsVgR}$ significantly reduced $\mathrm{VgR}$ expression, and worker ovarian development was affected, oviposition was delayed, and egg production was remarkably decreased. Our study provides insights into the reproductive regulation of fecundity in bumblebees. Therefore, the results of the present study provide basic knowledge of the reproductive biology of bumblebees.

Author Contributions: Conceptualization, L.D., J.H., and J.W.; methodology, L.D., M.W., and J.L.; software, L.D., J.H., and J.W.; validation, L.D., J.H., and S.H.; formal analysis, L.D.; data curation, L.D. and J.H.; writing-original draft preparation, L.D., J.H., and M.W.; writing-review and editing, L.D., J.H., S.H., and J.W.; visualization, L.D. and J.H.; supervision, J.W. and J.L.; project administration, J.H. and J.W.; and funding acquisition, J.H. and J.W.

Funding: This project was financially supported in part by the National Natural Science Foundation of China (U1603108), the China Agriculture Research System (CARS-44) and the Agricultural Science and Technology Innovation Program, CAAS (CAAS-ASTIP-2019-IAR).

Acknowledgments: We would like to thank Lei Han for her kindness in guiding the experiment.

Conflicts of Interest: The authors declare no conflict of interest. 


\section{References}

1. Velthuis, H.; Doorn, A. A century of advances in bumblebee domestication and the economic and environmental aspects of its commercialization for pollination. Apidologie 2006, 37, 421-451. [CrossRef]

2. Pywell, R.F.; Warman, E.A.; Carvell, C.; Sparks, T.H.; Dicks, L.V.; Bennett, D.; Wright, A.; Critchley, C.N.R.; Sherwood, A. Providing foraging resources for bumblebees in intensively farmed landscapes. Biol. Conserv. 2005, 121, 479-494. [CrossRef]

3. Roldan Serrano, A.; Guerra-Sanz, J.M. Quality fruit improvement in sweet pepper culture by bumblebee pollination. Sci. Hortic. 2006, 110, 160-166. [CrossRef]

4. Morandin, L.A.; Laverty, T.M.; Kevan, P.G. Effect of bumble bee (Hymenoptera: Apidae) pollination intensity on the quality of greenhouse tomatoes. J. Econ. Entomol. 2001, 94, 172-179. [CrossRef]

5. Tufail, M.; Takeda, M. Insect vitellogenin/lipophorin receptors: Molecular structures, role in oogenesis, and regulatory mechanisms. J. Insect Physiol. 2009, 55, 88-104. [CrossRef]

6. Raikhel, A.S.; Dhadialla, T.S. Accumulation of yolk proteins in insect oocytes. Annu. Rev. Entomol. 1992, 37, 217-251. [CrossRef]

7. Engelmann, F. Insect vitellogenin: Identification, biosynthesis, and role in vitellogenesis. Adv. Insect Physiol. 1979, 14, 49-108.

8. Amdam, G.V.; Norberg, K.; Fondrk, M.K.; Page, R.E. Reproductive ground plan may mediate colony-level selection effects on individual foraging behavior in honey bees. Proc. Natl. Acad. Sci. USA 2004, 101, 11350-11355. [CrossRef]

9. Corona, M.; Libbrecht, R.; Wurm, Y.; Riba-Grognuz, O.; Keller, L. Vitellogenin underwent subfunctionalization to acquire caste and behavioral specific expression in the harvester ant Pogonomyrmex barbatus. PLoS Genet. 2013, 9, e1003730. [CrossRef]

10. Cardoso Junior, C.; Oldroyd, B.; Ronai, I. Vitellogenin expression in the ovaries of adult honeybee workers provides insights into the evolution of reproductive and social traits. bioRxiv 2019, 547760. [CrossRef]

11. Röhrkasten, A.; Ferenz, H. Properties of the vitellogenin receptor of isolated locust oocyte membranes. Int. J. Invertebr. Reprod. Dev. 1986, 10, 133-142. [CrossRef]

12. Wu, H.; Jiang, F.; Guo, J.; Yi, J.; Liu, J.; Cao, Y.; Lai, X.; Zhang, G. Molecular characterization and expression of vitellogenin and vitellogenin receptor of Thitarodes pui (Lepidoptera: Hepialidae), an insect on the Tibetan Plateau. J. Insect Sci. 2018, 18, 1-7. [CrossRef] [PubMed]

13. Lin, Y.; Meng, Y.; Wang, Y.X.; Luo, J.; Katsuma, S.; Yang, C.W.; Banno, Y.; Kusakabe, T.; Shimada, T.; Xia, Q.Y. Vitellogenin receptor mutation leads to the oogenesis mutant phenotype scanty vitellin of the silkworm, Bombyx Mori. J. Biol. Chem. 2013, 288, 13345-13355. [CrossRef] [PubMed]

14. Kim, H.R.; Katagiri, C.; Nagao, E.; Chino, H. Purification and characterization of vitellogenin from the American cockroach, Periplaneta americana. Comp. Biochem. Physiol. B Comp. Biochem. 1992, 103, 963-967. [CrossRef]

15. Zhang, W.; Ma, L.; Xiao, H.; Xie, B.; Smagghe, G.; Guo, Y.; Liang, G. Molecular characterization and function analysis of the vitellogenin receptor from the cotton bollworm, Helicoverpa armigera (Hübner) (Lepidoptera, Noctuidae). PLoS ONE 2016, 11, e0155785. [CrossRef]

16. Tufail, M.; Takeda, M. Molecular cloning, characterization and regulation of the cockroach vitellogenin receptor during oogenesis. Insect Mol. Biol. 2005, 14, 389-401. [CrossRef]

17. Lu, K.; Shu, Y.; Zhou, J.; Zhang, X.; Zhang, X.; Chen, M.; Yao, Q.; Zhou, Q.; Zhang, W. Molecular characterization and RNA interference analysis of vitellogenin receptor from Nilaparvata lugens (Stål). J. Insect Physiol. 2015, 73, 20-29. [CrossRef]

18. Chen, M.E.; Lewis, D.K.; Keeley, L.L.; Pietrantonio, P.V. cDNA cloning and transcriptional regulation of the vitellogenin receptor from the imported fire ant, Solenopsis invicta Buren (Hymenoptera: Formicidae). Insect Mol. Biol. 2004, 13, 195-204. [CrossRef]

19. Ciudad, L.; Piulachs, M.D.; Bellés, X. Systemic RNAi of the cockroach vitellogenin receptor results in a phenotype similar to that of the Drosophila yolkless mutant. FEBS J. 2006, 273, 325-335. [CrossRef]

20. Lu, H.; Vinson, S.B.; Pietrantonio, P.V. Oocyte membrane localization of vitellogenin receptor coincides with queen flying age, and receptor silencing by RNAi disrupts egg formation in fire ant virgin queens. FEBS J. 2009, 276, 3110-3123. [CrossRef] 
21. Guidugli-Lazzarini, K.R.; Do Nascimento, A.M.; Tanaka, É.D.; Piulachs, M.D.; Hartfelder, K.; Bitondi, M.G.; Simões, Z.L.P. Expression analysis of putative vitellogenin and lipophorin receptors in honey bee (Apis mellifera L.) queens and workers. J. Insect Physiol. 2008, 54, 1138-1147. [CrossRef] [PubMed]

22. Hannon, G.J. RNA interference. Nature 2002, 418, 244-251. [CrossRef] [PubMed]

23. Amdam, G.V.; Simões, Z.L.; Guidugli, K.R.; Norberg, K.; Omholt, S.W. Disruption of vitellogenin gene function in adult honeybees by intra-abdominal injection of double-stranded RNA. BMC Biotechnol. 2003, 3, 1-8. [CrossRef] [PubMed]

24. Turner, C.T.; Davy, M.W.; MacDiarmid, R.M.; Plummer, K.M.; Birch, N.P.; Newcomb, R.D. RNA interference in the light brown apple moth, Epiphyas postvittana (Walker) induced by double-stranded RNA feeding. Insect Mol. Biol. 2006, 15, 383-391. [CrossRef]

25. Mao, Y.B.; Cai, W.J.; Wang, J.W.; Hong, G.J.; Tao, X.Y.; Wang, L.J.; Huang, Y.P.; Chen, X.Y. Silencing a cotton bollworm P450 monooxygenase gene by plant-mediated RNAi impairs larval tolerance of gossypol. Nat. Biotechnol. 2007, 25, 1307-1313. [CrossRef]

26. Costa, C.P.; Elias-Neto, M.; Falcon, T.; Dallacqua, R.P.; Martins, J.R.; Bitondi, M.M.G. RNAi-mediated functional analysis of bursicon genes related to adult cuticle formation and tanning in the honeybee, Apis mellifera. PLoS ONE 2016, 11, e0167421. [CrossRef]

27. Marco, A.D.; Guidugli-Lazzarini, K.R.; Do, N.A.; Simoes, Z.L.; Hartfelder, K. RNAi-mediated silencing of vitellogenin gene function turns honeybee (Apis mellifera) workers into extremely precocious foragers. Naturwissenschaften 2008, 95, 953-961. [CrossRef]

28. Garbian, Y.; Maori, E.; Kalev, H.; Shafir, S.; Sela, I. Bidirectional transfer of RNAi between honey bee and Varroa destructor: Varroa gene silencing reduces Varroa population. PLoS Pathog. 2012, 8, e1003035. [CrossRef]

29. An, J.D.; Huang, J.X.; Shao, Y.Q.; Zhang, S.W.; Wang, B.; Liu, X.Y.; Wu, J.; Williams, P.H. The bumblebees of North China (Apidae, Bombus Latreille). Zootaxa 2014, 3830, 1-89. [CrossRef]

30. Zhou, Z.; Zhang, H.; Liang, C.; Zou, Y.; Dong, J.; Yuan, X.; Huang, J.; An, J. Foraging preference of the honeybee Apis mellifera and the bumblebee Bombus lantschouensis (Hymenoptera: Apidae) in peach greenhouse. Acta Entomol. Sin. 2015, 58, 1315-1321.

31. Gurel, F.; Gosterit, A. Effects of different stimulation methods on colony initiation and development of Bombus terrestris L. (Hymenoptera: Apidae) queens. Appl. Entomol. Zool. 2008, 43, 113-117. [CrossRef]

32. Han, L.; Ding, G.; Liu, Y.; Huang, J.; Wu, J. Characterization of sphingomyelin phosphodiesterase expression in bumblebee (Bombus lantschouensis). J. Insect Sci. 2018, 18, 1-7. [CrossRef] [PubMed]

33. Rice, P.; Longden, I.; Bleasby, A. EMBOSS: The European molecular biology open software suite. Trends Genet. 2000, 16, 276-277. [CrossRef]

34. Krogh, A.; Larsson, B.; von Heijne, G.; Sonnhammer, E.L.L. Predicting transmembrane protein topology with a hidden markov model: Application to complete genomes. J. Mol. Biol. 2001, 305, 567-580. [CrossRef]

35. Almagro, A.J.; Tsirigos, K.D.; Sonderby, C.K.; Petersen, T.N.; Winther, O.; Brunak, S.; von Heijne, G.; Nielsen, H. SignalP 5.0 improves signal peptide predictions using deep neural networks. Nat. Biotechnol. 2019, 37, 420-423. [CrossRef]

36. Ivica, L.; Tobias, D.; Peer, B. SMART 7: Recent updates to the protein domain annotation resource. Nucleic Acids Res. 2011, 40, D302-D305.

37. Sudhir, K.; Glen, S.; Li, M.; Christina, K.; Koichiro, T. MEGA X: Molecular evolutionary genetics analysis across computing platforms. Mol. Biol. Evol. 2018, 6, 1547-1549.

38. Felsenstein, J. Confidence limits on phylogenies: An approach using the bootstrap. Evolution 1985, 4, 783-791. [CrossRef]

39. Livak, K.J.; Schmittgen, T.D. Analysis of relative gene expression data using real-time quantitative PCR and the 2(-Delta Delta C (T)) method. Methods 2001, 25, 402-408. [CrossRef]

40. Chen, J.; Zhang, D.; Yao, Q.; Zhang, J.; Dong, X.; Tian, H.; Chen, J.; Zhang, W. Feeding-based RNA interference of atrehalose phosphate synthase gene in the brown planthopper, Nilaparvata lugens. Insect Mol. Biol. 2010, 19, 777-786. [CrossRef]

41. Amdam, G.V.; Norberg, K.; Hagen, A.; Omholt, S.W. Social exploitation of vitellogenin. Proc. Natl. Acad. Sci. USA 2003, 100, 1799-1802. [CrossRef]

42. Dong, J.; Li, J.; Huang, J.; Wu, J. Identification of suitable reference genes for miRNA quantitation in bumblebee (Hymenoptera: Apidae) response to reproduction. Apidologie 2019, 50, 40-50. [CrossRef] 
43. Dohanik, V.T.; Gonçalves, W.G.; Oliveira, L.L.; Zanuncio, J.C.; Serrão, J.E. Vitellogenin transcytosis in follicular cells of the honeybee Apis mellifera and the wasp Polistes simillimus. Protoplasma 2018, 255, 1703-1712. [CrossRef]

44. Boldbaatar, D.; Battsetseg, B.; Matsuo, T.; Hatta, T.; Umemiya-Shirafuji, R.; Xuan, X.; Fujisaki, K. Tick vitellogenin receptor reveals critical role in oocyte development and transovarial transmission of Babesia parasite. Biochem. Cell Biol. 2008, 86, 331-344. [CrossRef]

45. Tufail, M.; Takeda, M. Molecular cloning and developmental expression pattern of the vitellogenin receptor from the cockroach, Leucophaea maderae. Insect Biochem. Mol. Biol. 2007, 37, 235-245. [CrossRef]

46. Chen, S.; Lee, T.; Ou, Y. Incorporating significant amino acid pairs to identify O-linked glycosylation sites on transmembrane proteins and non-transmembrane proteins. BMC Bioinform. 2010, 11, 536. [CrossRef]

47. Cong, L.; Yang, W.; Jiang, X.; Niu, J.; Shen, G.; Ran, C.; Wang, J. The essential role of vitellogenin receptor in ovary development and vitellogenin uptake in Bactrocera dorsalis (Hendel). Int. J. Mol. Sci. 2015, 16, 18368-18383. [CrossRef]

48. Hiramatsu, N.; Chapman, R.W.; Lindzey, J.K.; Haynes, M.R.; Sullivan, C.V. Molecular characterization and expression of vitellogenin receptor from white perch (Morone americana). Biol. Reprod. 2004, 70, 1720-1730. [CrossRef]

49. Piulachs, M.D.; Guidugli, K.R.; Barchuk, A.R.; Cruz, J.; Simoes, Z.L.; Belles, X. The vitellogenin of the honey bee, Apis mellifera: Structural analysis of the cDNA and expression studies. Insect Biochem. Mol. Biol. 2003, 33, 459-465. [CrossRef]

50. Herz, J.; Gotthardt, M.; Willnow, T.E. Cellular signalling by lipoprotein receptors. Curr. Opin. Lipidol. 2000, 11, 161-166. [CrossRef]

51. Gotthardt, M.; Trommsdorff, M.; Nevitt, M.F.; Shelton, J.; Richardson, J.A.; Stockinger, W.; Nimpf, J.; Herz, J. Interactions of the low density lipoprotein receptor gene family with cytosolic adaptor and scaffold proteins suggest diverse biological functions in cellular communication and signal transduction. J. Biol. Chem. 2000, 275, 25616-25624. [CrossRef] [PubMed]

52. Li, J.; Huang, J.; Cai, W.; Zhao, Z.; Peng, W.; Wu, J. The vitellogenin of the bumblebee, Bombus hypocrita: Studies on structural analysis of the cDNA and expression of the mRNA. J. Comp. Physiol. B 2010, 180, 161-170. [CrossRef] [PubMed]

53. Cho, K.H.; Raikhel, A.S. Organization and developmental expression of the mosquito vitellogenin receptor gene. Insect Mol. Biol. 2001, 10, 465-474. [CrossRef] [PubMed]

54. Kim, B.Y.; Lee, K.S.; Yoon, H.J.; Kim, I.; Li, J.; Sohn, H.D.; Jin, B.R. Expression profile of the iron-binding proteins transferrin and ferritin heavy chain subunit in the bumblebee Bombus ignitus. Comp. Biochem. Physiol. B Biochem. Mol. Biol. 2009, 153, 165-170. [CrossRef]

55. Nunes, F.M.F.; Aleixo, A.C.; Barchuk, A.R.; Bomtorin, A.D.; Grozinger, C.M.; Simões, Z.L.P. Non-target effects of green fluorescent protein (GFP)-derived double-stranded RNA (dsRNA-GFP) used in honey bee RNA interference (RNAi) assays. Insects 2013, 4, 90-103. [CrossRef]

56. Duncan, E.J.; Hyink, O.; Dearden, P.K. Notch signalling mediates reproductive constraint in the adult worker honeybee. Nat. Commun. 2016, 7, 12427. [CrossRef]

57. Genissel, A.; Aupinel, P.; Bressac, C.; Tasei, J.N.; Chevrier, C. Influence of pollen origin on performance of Bombus terrestris micro-colonies. Entomol. Exp. Appl. 2010, 104, 329-336. [CrossRef]

58. Babendreier, D.; Reichhart, B.; Romeis, J.; Bigler, F. Impact of insecticidal proteins expressed in transgenic plants on bumblebee microcolonies. Entomol. Exp. Appl. 2010, 126, 148-157. [CrossRef]

59. Dance, C.; Botías, C.; Goulson, D. The combined effects of a monotonous diet and exposure to thiamethoxam on the performance of bumblebee micro-colonies. Ecotoxicol. Environ. Saf. 2017, 139, 194-201. [CrossRef]

(C) 2019 by the authors. Licensee MDPI, Basel, Switzerland. This article is an open access article distributed under the terms and conditions of the Creative Commons Attribution (CC BY) license (http://creativecommons.org/licenses/by/4.0/). 